\title{
Measurement and Evaluation of the Spectral Duty Cycle in a Wi-Fi Network
}

\author{
Hubert A. Santander R. ${ }^{\# 1}$, Michael A. Prada M. ${ }^{\# 2}$, Cesar Hernández ${ }^{\# 3}$ \\ \# Technology Faculty, Universidad Distrital Francisco José de Caldas \\ 68 Street D Bis A South No. 49F - 70, Bogotá, Colombia \\ ${ }^{1}$ hasantanderr@correo.udistrital.edu.co \\ 2 mapradam@correo.udistrital.edu.co \\ 3 cahernandezs@udistrital.edu.co
}

\begin{abstract}
The measurement of the spectral occupation based on the duty cycle, is a very important subject when it comes to designing and dimensioning Wi-Fi wireless networks. This article aims to present the measurement, analysis and evaluation of the spectral occupation of the Wi-Fi network (2.4 $2.5 \mathrm{GHz}$ ) from the Faculty of Technology of District University Francisco Jose de Caldas. In order to determine the Wi-Fi network's duty cycle level, a campaign took place for measuring the spectral occupation in the 2.4 to $2.5 \mathrm{GHz}$ frequency band, during a month. Such data was later processed and analyzed. The obtained results show that Wednesdays are when the highest spectral occupation occurs with $95 \%$ utilization. As a conclusion, it is important to know the levels of spectral use in the wireless WiFi networks in order to determine the most suitable redesign that ensures a great signal quality and satisfies the university's community.
\end{abstract}

Keyword - duty cycle, spectral occupation, reception potency, Wi-Fi network.

\section{INTRODUCTION}

During the last few years, the use, presence and study of Wi-Fi technology has been extending continuously [1]. Nowadays, this technology is present in almost every part of the world and it has become a fundamental need when it comes to higher education, therefore, the implementation of this networks in universities is more common every time.

The importance of Wi-Fi networks in the academic and investigative processes has turned it into a relevant tool within the university's campus and therefore, its service quality is so interesting for all the university's community [2]. However, students nowadays are somehow dissatisfied regarding the performance of the Wi-Fi network from the Faculty of Technology of District University Francisco Jose de Caldas.

This is why the main purpose of this article is to measure and evaluate the spectral duty cycle of the Wi-Fi Network from the Faculty of Technology of District University Francisco Jose de Caldas, in order to determine if the current spectral occupation level is considerably high. Such study will allow to determine the necessity for redesigning the Wi-Fi network or raising alternate solutions [3].

In [4] highlights today’s importance of Wi-Fi networks as an essential tool for the university's students and teachers. Therefore, knowing its capacity and performance level is a general interest for the university's community.

This article is structured as follows. Section II presents the related work. Section III describes the investigation's methodology. Section IV shows the obtained results. Finally, section V presents the conclusions.

\section{RELATED WORK}

In [5] makes a spectrum measurement campaign in order to determine the actual occupation if the ISM band within a high user density environment. Although many wireless technologies share this frequency band, the results show its low spectrum utilization. Indeed, it shows that spectral occupation on a regular duty day is moderate, therefore, using a more sophisticated approach is essential in order to explode the access to this band without any license, for which the cognitive radio is very suitable.

In [6] determines that the spectrum's detection is a very important tool when it comes to expanding the cognitive radio. This work evaluates the use for tests in order to optimize the available frequency's spectral detection. The simulation's results show that these statistical tests are useful and can be applied to wireless cognitive channels that are subjected to fading.

In [7] analyzes the spectral occupation of the frequency band among 75 y $7075 \mathrm{MHz}$ within an external urban environment and a posteriori compare them to an internal environment. The obtained results demonstrate that some spectrum bands are subject to intense use, while some others show moderate utilization levels, others are little used and, in some cases, they are not used at all. In general, the average spectrum's occupation observed in frequency and time in this study was found to be significantly low, concretely $17.78 \%$ for the whole spectrum (75 a $7075 \mathrm{MHz}$ ). 
A group of investigators from Washington University has developed a technology that takes advantage of an already known effect which so far had not been successfully applied [8]. Their system called Passive Wi-Fi, allows applying the backscatter from regular Wi-Fi networks in order to create specific channels which could be used for IoT devices. The transmissions are not fully passive, instead, they use the transmissions made by other devices around in order to emit information at rates that go up to $11 \mathrm{Mbps}$.

\section{III.METHODOLOGY}

The first step upon developing the current investigation's methodology was to make a measurement of the Wi-Fi network usage levels, through the registry of signal potency in two different spots at the Faculty of Technology of District University Francisco Jose de Caldas

\section{A. Spectral Occupation's data capture}

In order to make the potency registry of the Wi-Fi network, the spectrum analyzer was used: Signal Hound USB-SA44B and a laptop. The spectrum analyzer was placed in two different spots of the University as shown in Fig. 1. The first spot was the software room located in block 4, floor 3; the second spot was the electric machines laboratory located in block 12, floor 2.

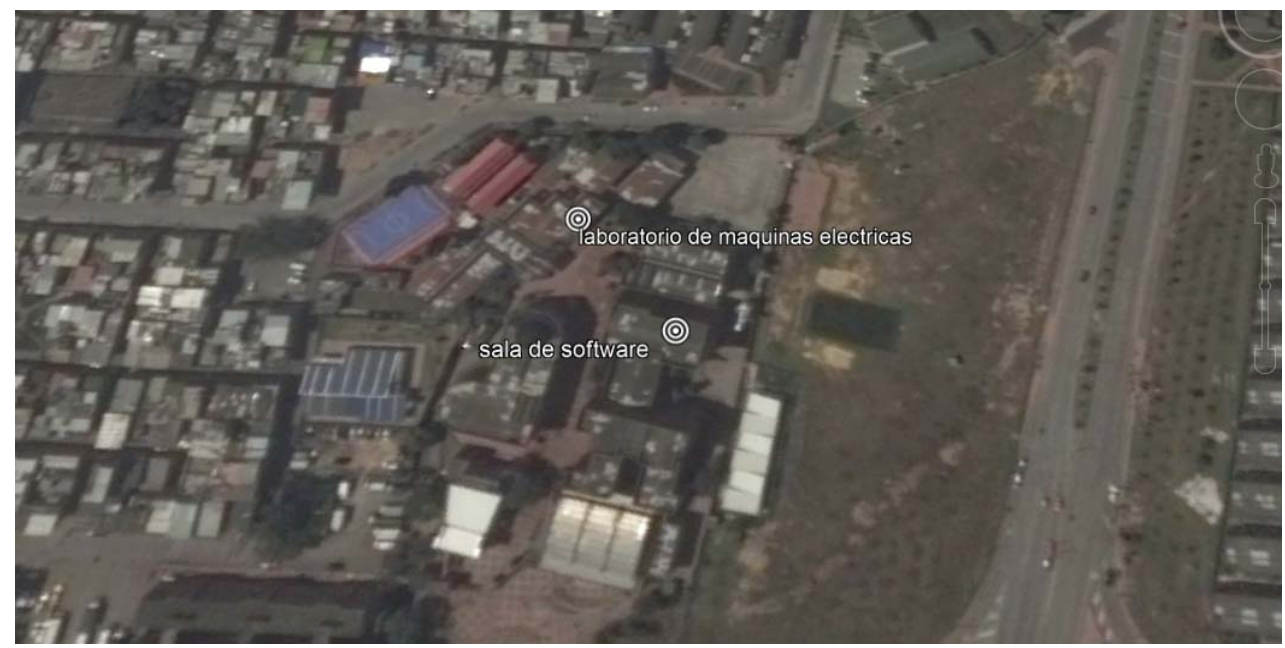

Fig. 1. Location of the Spectrum's Analyzer

For each spot, the spectrum's analyzer made a spectral information registry between 6:00 a.m. and 8:00 p.m. During each hour of that period, a proprietary format file was generated and stored in a laptop. The spectral measurement process was made during one month, 15 days in each spot from Fig. 1.

\section{B. Spectral information's organization}

Because the spectrum's analyzer stores information about the potency levels of the signal in a proprietary format (.BBR), it was necessary to export them to Excel files in a CSV format, through the Spike software. Later, the spectral information: date, time, potency and frequency contained in the .CSV file was organized into separate columns and stored in .XLS format

Finally, the information contained in each Excel file (.XLS) was merged into one single file, generating a data base with all the information delivered by the spectrum's analyzer in an organized way, allowing to make an analysis of the signal's potency by day, time or frequency.

\section{Wi-Fi channels spectral information}

Due to the configuration parameters of the spectrum's analyzer, such as Sweep Time, Resolution Bandwide (RBW) and Span, the information of the signal's potency was not found by Wi-Fi cannel but by way narrower frequency segments, reason why they took the number of segments corresponding to each Wi-Fi channel and averaged the respective potency levels in order to obtain a single value for each Wi-Fi channel.

According to the rule IEEE 802.11 stablishes that wireless devices can be use the $2.4 \mathrm{GHz}$ frequency band, which is subdivided into 14 channels in the case of Colombia, separated by a minimum frequency of $5 \mathrm{MHz}$. The central frequency of each Wi-Fi channel can be observed in table 1 
TABLE I. Wi-Fi Channels Central Frequency

\begin{tabular}{|c|c|c|c|c|c|c|c|c|c|c|c|c|c|c|}
\hline Channel & 1 & 2 & 3 & 4 & 5 & 6 & 7 & 8 & 9 & 10 & 11 & 12 & 13 & 14 \\
\hline $\begin{array}{l}\text { Frecuency } \\
(\mathrm{GHz})\end{array}$ & 2.412 & 2.417 & 2.422 & 2.427 & 2.432 & 2.437 & 2.442 & 2.447 & 2.452 & 2.457 & 2.462 & 2.467 & 2.472 & 2.484 \\
\hline
\end{tabular}

Each Wi-Fi cannel has a $22 \mathrm{MHz}$ bandwidth, therefore, if we chose channel 6, which operates in the 2.437 $\mathrm{GHz}$ central frequency, its bandwidth goes from $2.415 \mathrm{GHz}$ to $2.459 \mathrm{GHz}$.

D. Spectral occupation calculation

In order to determine the normalized duty cycle of each Wi-Fi cannel, the noise floor from the spectrum's analyzer was used as reference, and in order to have a good error margin, $5 \mathrm{dBm}$ were added above that level, the resulting value was $80 \mathrm{dBm}$ which was used as reference threshold to calculate the availability of each channel in each time instant. (View equation (1) and (2)).

$$
\begin{gathered}
\text { Detected potency in the cannel }<\text { Reference threshold => Available channel } \\
\text { Detected potency in the cannel }>\text { Reference threshold => Busy Channel }
\end{gathered}
$$

The availability information was stored through a binary variable, where ' 1 ' indicates the channels is busy and ' 0 ' that the channel is available

\section{E. Duty cycle}

The procedure for calculating the normalized duty cycle was made by time, in order to make a detailed analysis of the spectral occupation and determine the times with the highest Wi-Fi network usage levels. Such calculation is based on the availability average of each channel per measurement hour, as shown in equation (3).

$$
\text { Normalized duty cycle }=\frac{1}{k} \sum_{i-1}^{k} x_{\tau}
$$

Where $\mathrm{x}$ is the value of the availability in instant $\mathrm{t}$, and $\mathrm{k}$ is the number of time instants.

Then, in order to condense more the data from the spectral information, an average is made upon the signal potency measured in $\mathrm{dBm}$ for each hour of the captured time period. A sample of this information is shown in Table 2.

TABLE III. Spectral Information Organized by Time

\begin{tabular}{|c|c|c|c|c|}
\hline $\begin{array}{c}\text { Wi-Fi } \\
\text { channel }\end{array}$ & Time & $\begin{array}{c}\text { Average Potency } \\
(\mathrm{dBm})\end{array}$ & $\begin{array}{c}\text { Duty } \\
\text { Cycle }\end{array}$ & Availablity \\
\hline \multirow{3}{*}{ Canal 1 } & $6: 00$ a. $\mathrm{m}$. & -79.574 & 0.490 & 1 \\
\hline & 7:00 a. m. & -81.215 & 0.109 & 0 \\
\hline & $8: 00$ a. m. & -81.022 & 0.145 & 0 \\
\hline & $9: 00$ a. m. & -79.447 & 0.690 & 1 \\
\hline & $10: 00$ a. $\mathrm{m}$. & -83.526 & 0.000 & 0 \\
\hline
\end{tabular}

Finally, it was observed that there was a similar behavior for each day of the week, which is why the information was organized according to each day of the week, taking the interest variables average in order to have a unique duty cycle value for all Mondays, Tuesdays, Wednesdays, Thursdays and Fridays. A sample from the obtained result can be observed in Table 3.

TABLE IIIII. Normalized Working Cycle for Cannel by Working Day

\begin{tabular}{|l|l|l|l|l|l|l|}
\hline Wi-Fi \\
Channel
\end{tabular}




\section{IV.RESULTS}

After completing the procedure for one week, we obtained the duty cycle for each working day, morning, afternoon and night. For the morning, we averaged the duty cycle by day from 6:00 a.m. to 12:00 a.m., for the afternoon from 12:00 p.m. to 6:00 p.m. and for the night from 6:00 p.m. to 8:00 p.m. Finally, we graphed the normalized duty cycle for each working day, obtaining Fig. 2 to 6.

From Fig. 2 it can be observed that Monday has a spectral occupation level fluctuating between 20\% and $50 \%$ for the morning, in the afternoon the spectral occupation increases, even above $60 \%$, mainly in central channels 6, 7 and 8, and in the night the spectral occupation es the lowest compared to the two previous frame times, with a maximum of $39 \%$ in channels 8 and 9.

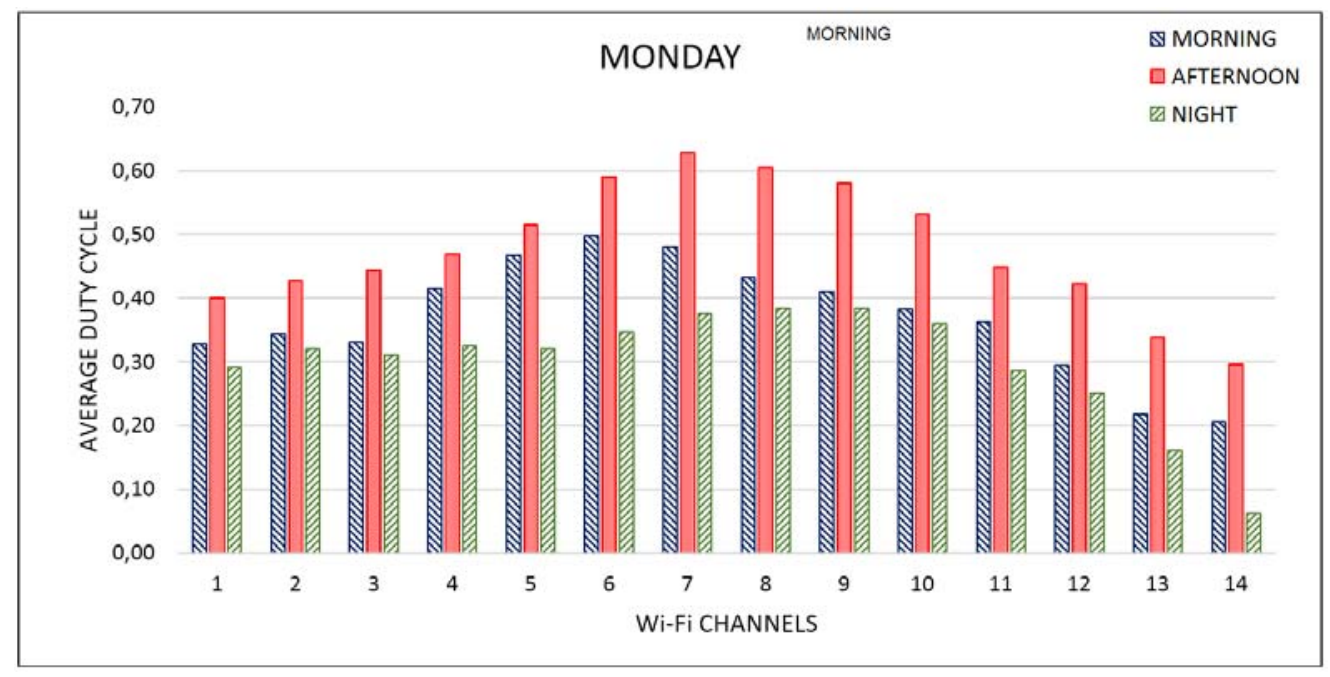

Fig. 2. Behavior of the Spectral Occupation on Monday

From Fig. 3, it can be observed that Tuesday has an average spectral occupation higher than Monday's for the three frame times. However, the night shift shows more activity than both the morning and the afternoon. Furthermore, the spectral occupations of the afternoon and the night have a very similar behavior, with a 70 to $80 \%$ fluctuation.

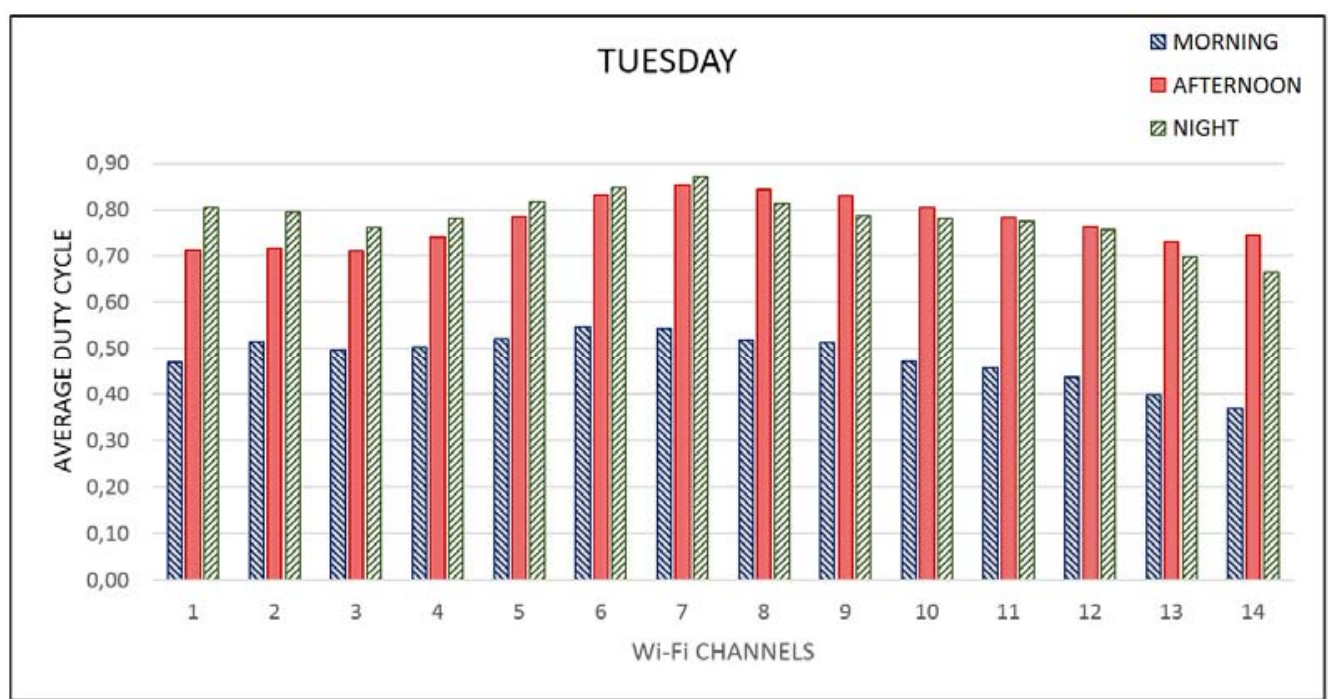

Fig. 3. Behavior of the Spectral Occupation on Tuesday

In Fig. 4 it can be observed that Wednesday shows a high wireless network usage, especially during the afternoon with 95\% spectral occupation in all channels, followed by the night and the morning, with approximately $72 \%$ and $60 \%$, respectively. 


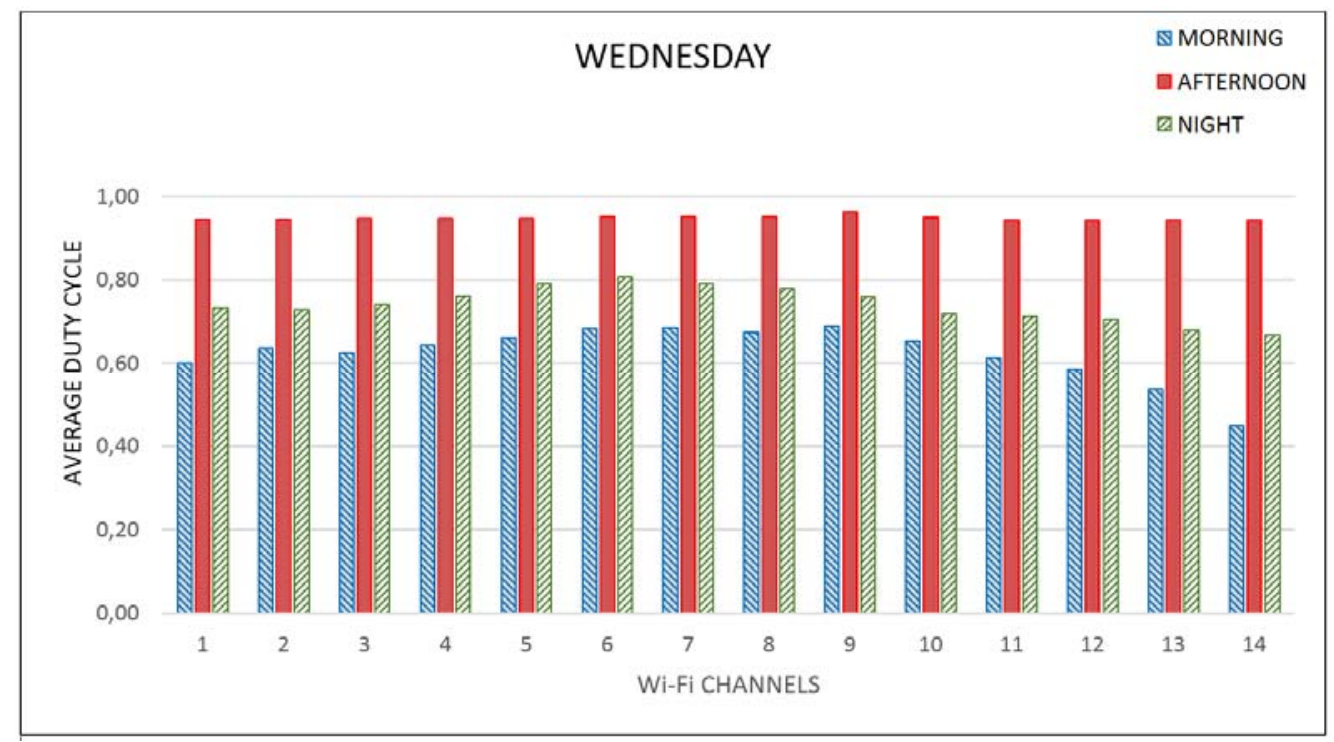

Fig. 4. Behavior of the Spectral Occupation on Wednesday.

In Fig. 5 it can be observed that Thursday's usage has a spectral occupation with a decreasing tendency, the highest activity on the wireless network is registered during the morning with a maximum of $72 \%$, in channel 10 , the same channel in the afternoon registers a maximum of $52 \%$. Additionally, the afternoon shift shows a significant variability on the spectral occupation of every channel. Finally, the night shift presents a very low spectral occupation with maximum of $23 \%$, even in channel 14 the occupation percentage drops to 0 .

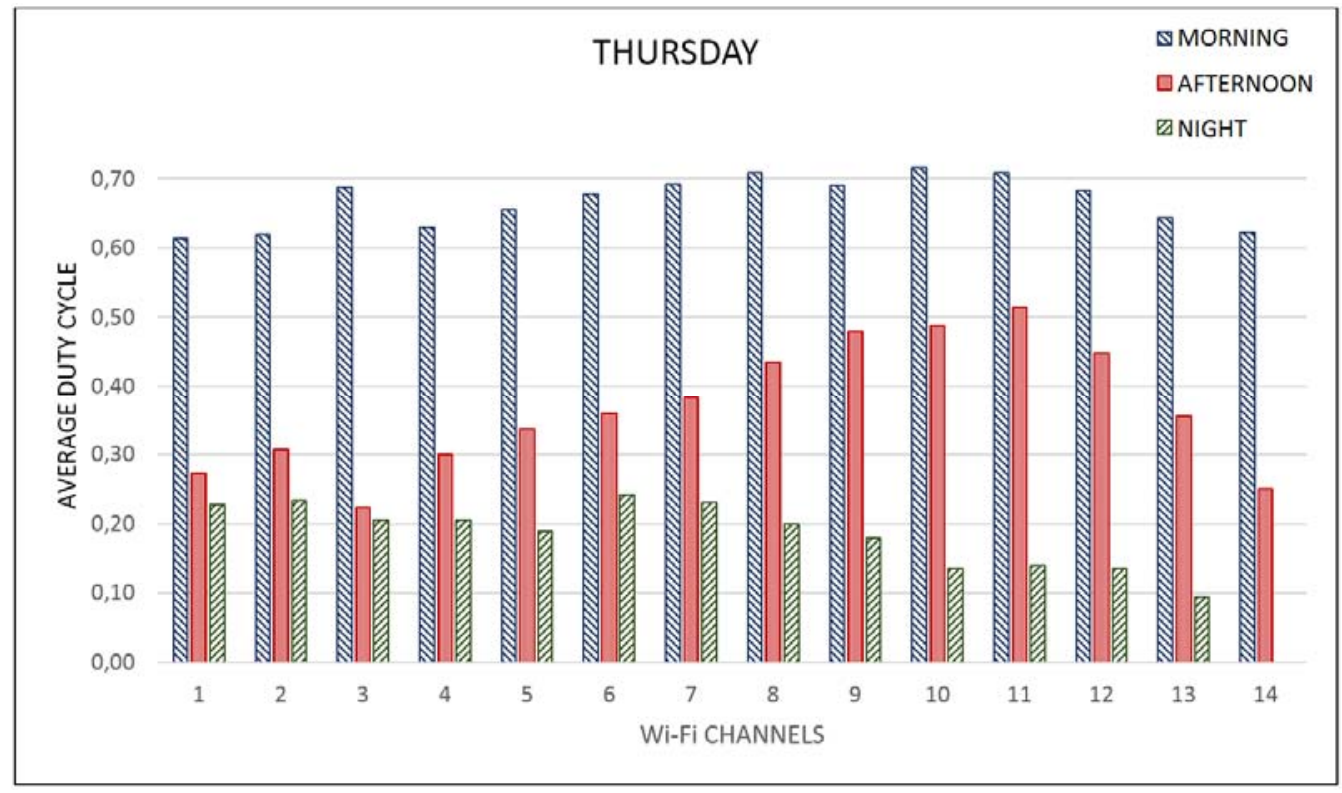

Fig. 5. Behavior of the Spectral Occupation on Thursday.

In Fig. 6, it can be observed that Friday has a higher activity during the morning and the night, resulting into a decreasing tendency with a minimum of $9 \%$ in the afternoon. The night has the highest spectral occupation of the day, with a maximum of $64 \%$, while the morning shows little stability in usage, fluctuating between $28 \%$ and $49 \%$. 


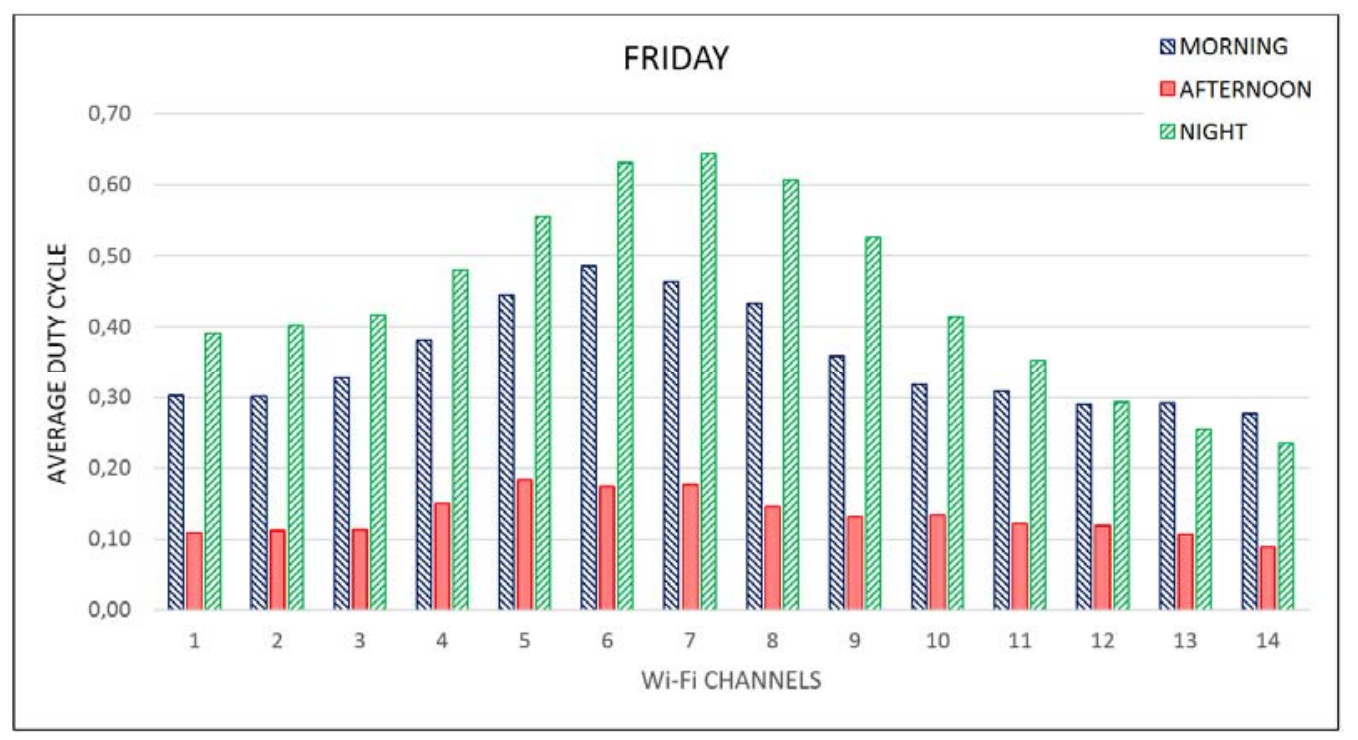

Fig. 6. Behavior of the Spectral Occupation on Friday.

Considering the results and after analyzing every day of the week, it can be concluded that Wednesday is the day with the highest spectral occupation level, therefore, causing saturation in many channels even resulting into a loss of the Wi-Fi network connection.

\section{Conclusion}

According to the results obtained during the investigation, it was clear that the demand of users of the Wi-Fi network from the Faculty of Technology of District University Francisco Jose de Caldas is higher than its own capacity, limiting thus its data transfer level. This makes it necessary to create a Wi-Fi network design that allows guaranteeing a proper service quality level for developing academic and investigative works.

Since several Wi-Fi channels overlap, one of the most commonly used channel combinations for 802.11 access points that signal does not overlap, are the channels 1, 6, and 11. From channel 1 (2412 MHz) the first channel separated by at least $22 \mathrm{MHz}$ is 6 (2437 MHz), $25 \mathrm{MHz}$ apart from the channel 1 . And the first channel separated by at least $22 \mathrm{MHz}$ from channel 6 is $11(2462 \mathrm{MHz})$, also at $25 \mathrm{MHz}$ from channel 6 .

\section{ACKNOWLEDGMENT}

The present research is part of the research project "Spectral occupation prediction model for the analysis and design of cognitive radio networks", funded by the Center for Scientific Research and Development of the Universidad Distrital Francisco José de Caldas.

\section{REFERENCES}

[1] E. Rodriguez, "Evolucion de las redes inalambricas,” Maest. del web Editor., 2008

[2] K. Kosek-szott, J. Gozdecki, K. Loziak, M. Natkaniec, L. Prasnal, S. Szott, and M. Wagrowski, "Coexistence Issues in Future WiFi Networks,” no. August, pp. 86-95, 2017.

[3] C.-L. Wang, M.-C. Jan, Y.-S. Chang, E. Wang, and Y.-H. Lin, "Adaptive Out-of-Band Interference Suppression for Coexistent WiFi and Bluetooth Systems,” IEEE Commun. Lett., vol. 7798, no. c, pp. 1-1, 2017.

[4] D. Hing, Vutha; Lun, Pide; Phann, "IEEE 802.11AX: Challenges and Requirements for Future High Efficiency Wi-Fi,” no. CDRI Publication, pp. 2-9, 2011.

[5] M. Cardenas-juarez, M. A. Diaz-ibarra, U. Pineda-rico, A. Arce, and E. Stevens-navarro, "On Spectrum Occupancy Measurements at 2 . 4 GHz ISM Band for Cognitive Radio Applications,” in International Conference on Electronics, Communications and Computers, 2016, pp. 25-31.

[6] F. B. S. Carvalho, W. T. A. Lopes, and M. S. Alencar, "Cognitive spectrum sensing via statistical tests in rice fading channels,” 2016 39th Int. Conf. Telecommun. Signal Process. TSP 2016, pp. 157-160, 2016.

[7] S. Molina, "Análisis y caracterización de la ocupación espectral en diversos escenarios urbanos exteriores en el contexto de redes Cognitive Radio de acceso dinámico al espectro,” p. 132, 2009.

[8] V. Liu, A. Parks, V. Talla, S. Gollakota, D. Wetherall, and J. R. Smith, "Ambient Backscatter: Wireless Communication Out of Thin Air,” Acm Sigcomm Comput. Commun. Rev., vol. 43, no. 4, pp. 39-50, 2013. 


\section{Author Profile}

Hubert A. Santander R. Professional in Technology in Electricity at Universidad Distrital Francisco José de Caldas, Bogotá, Colombia.

Michael A. Prada M. Professional in Technology in Electricity at Universidad Distrital Francisco José de Caldas, Bogotá, Colombia.

Cesar Augusto Hernandez Suarez Electronic Engineer, Master in Information Science and Communications, Doctor of Philosophy in Systems and Computer Engineering of the Universidad Nacional de Colombia. Professor and researcher at Universidad Distrital Francisco José de Caldas, Bogotá, Colombia. 